\title{
Closed-loop Supply Chain with Advertising Investment and Reward-Penalty Mechanism Based on Different CSR Sharing Models
}

\author{
Yi Liu ${ }^{1, a}$, Yanting Huang*2,b \\ ${ }^{1}$ College of Management, Shenzhen University, Shenzhen, China \\ ${ }^{2}$ College of Management, Shenzhen University, Shenzhen, China
}

\begin{abstract}
This paper considers a closed-loop supply chain (CLSC) consisting of a manufacturer and a retailer based on different corporate social responsibility (CSR) behaviors. In addition, the advertising investment and government's reward-penalty mechanism (RPM) are also taken in account. To explore the impact of CSR behaviors on supply chain, we developed three models: (1) Only the manufacturer undertakes CSR (model M); (2) only the retailer undertakes CSR (model R); (3) the manufacturer and the retailer share CSR (model MR). By analyzing the results, we found that: (1) The advertising investment level and waste products return rate both increase with the increase of the extent to members undertake CSR when there is only retailer undertakes CSR and when the manufacturer and retailer share CSR, and remain unchanged when there is only the manufacturer undertakes CSR; (2) the overall social welfare increases with the increase of the extent to members undertake CSR no matter which member undertakes CSR, and reaches the highest when there is only the retailer undertakes CSR; (3) it is the most conductive for the performance of the closedloop supply chain when there is only the retailer undertakes CSR.
\end{abstract}

\section{Introduction}

The considerable economic and environmental benefits from recycling and remanufacturing have made closedloop supply chain ( CLSC ) management become a research hotspot for many scholars. For example, Savaskan et al. 1 used the Stackelberg game model to study the structure selection of the CLSC and the advantages and disadvantages of different recycling modes. Atasu et al. 2 explored the recycling channels of remanufacturers under different recycling cost structures. Ata et al. 3 focused on the impact of different incentives such as carbon emission reduction on supply chain performance.

The government has long offered reward-penalty mechanism (RPM) to manufacturers to support the development of recycling and remanufacturing activities. It is known that RPM has significantly impacts and is a driving force in the process of recycling and remanufacturing of waste products. Wang et al. 4 studied responsibility sharing between the manufacturer and the third-party recycler, and identified an RPM for government to motivate recycling endeavor. Wang et al. 5 investigated RPM for a CLSC with two sequential competing manufacturers by using game theoretic models. Kim et al. 6 examined the return rate of waste products and greening improvement level decisions in a three-level CLSC considering the RPM and subsidy policy. However, among all the above research on the CLSC, the RPM is as an endogenous variable, instead of an exogenous variable.

Otherwise, almost all existing research considering government's RPM ignore the impact of corporate social responsibility behaviors of enterprises on the coordination of CLSC. Besides pursuing profits, more and more international enterprises have begun to pay attention to sustainable development and corporate social responsibility (CSR) . Corporate social responsibility refers enterprises must also assume responsibilities to more stakeholders such as consumers, communities and the environment when creating profits. Panda et al. 7 discussed the channel coordination of CLSC with social responsibility from the perspective of profit maximization and recycling activities. Nikunja et al. 8 developed a socially responsible CLSC model that using donation as a CSR activity to investigate the structure of a two-echelon CLSC. Seyyed-Mahdi 9 proposed an analytical coordination mechanism to coordinate CSR and the dualfunction acquisition price in a CLSC. Wang et al. 10 constructed three modes to discuss decision making of CLSC with CSR behaviors and fairness concerns.

What is more, from the perspective of the internal operation of the CLSC, advertising will not only affect the sales of new products, but also contributes to the recycling and remanufacturing of waste products. Currently, some scholars have already carried out in-depth studies on the effects of advertisement on CLSC. Hong et al. 11 explored

${ }^{\mathrm{b} C}$ Corresponding author: ythuang4028@szu.edu.cn 
the optimal decisions of local advertising, product recycling and pricing in centralized and decentralized CLSC by constructing Stackelberg game models. Régis 12 studied the interplay between dynamic price, advertising policies, and product quality under an optimal control model. Ata et al. 13 addressed pricing and reverse channel selection decisions in a CLSC under fuzzy parameters of selling price function and advertising level function. But most of the current research are only focus on the impact of advertisement, few studies consider advisement with CSR behavior and government's reward-penalty mechanism.

To fill such research gap, the purpose of this paper is to figure out the role of CSR behavior considering government's RPM and advertising investments in a recycling CLSC and to have a better understanding on the distribution of CSR behavior between chain members at an optimal level and the impacts of CSR behavior on the performance of CLSC and overall social welfare. Hence, in this research, we address the following research questions:

(1) Taking government's RPM into account, which chain member to undertake CSR is better for the used products return rate of manufacturer?

(2) Taking government's RPM into account, which chain member to undertake CSR is better for the advertising investment level of retailer?

(3) Taking government's RPM into account, which chain member to undertake CSR is better for the overall social welfare of the CLSC?

\section{Problem description}

Considering a CLSC composed of a single manufacturer, a single retailer, and consumers. The manufacturer is responsible for producing new products and recycling waste products, while the retailer is responsible for advertising and selling products. To explore the effects of different chain members undertaking CSR on the supply chain, we develop a basic model and three different CSR sharing models: (1) Neither the manufacturer nor the retailer undertakes the CSR (Basic model C); (2) only the manufacturer undertakes CSR (model M); (3) only the retailer undertakes CSR (model R); (4) the manufacturer and the retailer share the CSR (model MR).

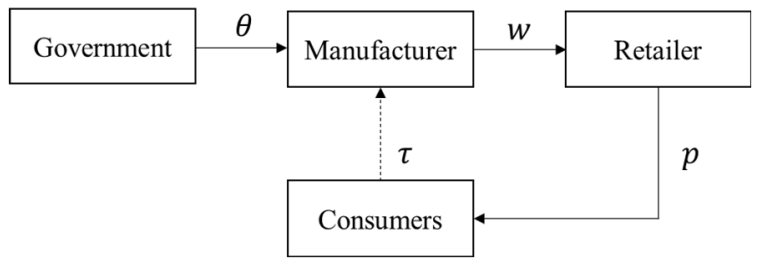

Figure 1 The CLSC

\subsection{Model assumptions}

The assumptions of this paper are as follows:

(1) The information in the market is complete and symmetrical, and enterprises fully understand each other's information.
(2) The new products and remanufactured products are regarded as homogeneous products, consumers have the same acceptance of them 1 .

(3) The enterprises in the supply chain are economically rational, that is, satisfy $p>w>c_{n}>c_{r}>$ 0 .

\subsection{Parameters description}

The parameters used in this paper are described as follows:

Table1. Parameter description

\begin{tabular}{|c|c|}
\hline Parameters & Description \\
\hline$w$ & Wholesale price of each product \\
\hline$p$ & Selling price of each product, $p>w$ \\
\hline$c_{n}$ & $\begin{array}{l}\text { Fixed production cost per unit of products, } \\
\qquad p>w\end{array}$ \\
\hline$c_{r}$ & $\begin{array}{c}\text { Remanufacturing cost of each waste } \\
\text { product }\end{array}$ \\
\hline$\Delta$ & $\begin{array}{l}\text { Cost advantage of each product for } \\
\text { remanufacturing, } \Delta=c_{n}-c_{r}>0\end{array}$ \\
\hline$\tau$ & $\begin{array}{l}\text { Return rate of waste products, } 0 \leq \tau \leq 1 \text {. } \\
\text { The relationship between the investment in } \\
\text { recycling activities and the return rate } \\
\text { satisfies } I=k \tau^{2} \text {, to simplify the } \\
\text { calculation, take } k=\frac{1}{2} \text {, so the } \\
\text { manufacturer's investment in recycling } \\
\text { activities } I=\frac{\tau^{2}}{2} 14\end{array}$ \\
\hline$g$ & $\begin{array}{l}\text { Advertising investment levels of the } \\
\text { retailer, the relationship between } \\
\text { advertising cost and investment level is } \\
g=\sqrt{\gamma C} \text {. To simplify the calculation, let } \\
\gamma=2 \text {, so the advertising cost in this paper } \\
\text { is } C=\frac{g^{2}}{2} 15\end{array}$ \\
\hline$D$ & $\begin{array}{c}D=\alpha-\beta p+\lambda g, \alpha \text { is the market } \\
\text { capacity, } \beta \text { is he sensitivity of demand to } \\
\text { price and } \lambda \text { is the sensitivity of demand to } \\
\text { advertising }\end{array}$ \\
\hline$r$ & $\begin{array}{l}\text { The extent to which supply chain members } \\
\text { undertake CSR, } 0 \leq r \leq 1\end{array}$ \\
\hline$C S$ & $\begin{array}{l}\text { Consumer Surplus. } C S=\int_{p \min }^{p \max } D d p= \\
\qquad \frac{(\alpha-\beta p+\lambda g)^{2}}{2 \beta} 7\end{array}$ \\
\hline$k$ & Manufacturer's share of CSR, $0<k<1$ \\
\hline$\tau_{0}$ & $\begin{array}{c}\text { Target waste products return rate according } \\
\text { to government regulations }\end{array}$ \\
\hline$\theta$ & $\begin{array}{l}\text { Government rewards and punishments for } \\
\text { manufacturer }\end{array}$ \\
\hline$\pi_{m}$ & $\begin{array}{l}\text { The net profit of manufacturer under } \\
\text { different CSR sharing models }\end{array}$ \\
\hline$\pi_{r}$ & $\begin{array}{l}\text { The net profit of retailer under different } \\
\text { CSR sharing models }\end{array}$ \\
\hline$V_{m}$ & $\begin{array}{l}\text { The social welfare of manufacturer under } \\
\text { different CSR sharing models }\end{array}$ \\
\hline
\end{tabular}




\begin{tabular}{c|c}
$V_{r}$ & $\begin{array}{c}\text { The social welfare of retailer under } \\
\text { different CSR sharing models }\end{array}$ \\
$V_{S}$ & $\begin{array}{c}\text { The overall social welfare of CLSC under } \\
\text { different CSR sharing models }\end{array}$ \\
\hline
\end{tabular}

\section{Model analysis}

\subsection{Basic model C-Neither the manufacturer nor the retailer undertakes the CSR}

In this model, none of the CLSC members undertakes the CSR. The profit functions of CLSC members are as follow: $\operatorname{Max} \pi_{m}^{C}=\left(w-c_{n}+\Delta \tau\right)(\alpha-\beta p+\lambda g)+\theta\left(\tau-\tau_{0}\right)-$ $h \tau^{2}(1)$

$$
\operatorname{Max} \pi_{r}^{C}=(p-w)(\alpha-\beta p+\lambda g)-\frac{1}{2} g^{2}
$$

The relationship between the profit $\pi$ and $g$ and $\tau$ can be demonstrated as the following Hessian matrix:

$$
H=\left|\begin{array}{cc}
-h & \lambda \Delta \\
\lambda \Delta & -1
\end{array}\right|=h-(\lambda \Delta)^{2}>0
$$

It can be convinced that the profit $\pi$ is strictly jointly concave in $g$ and $\tau$.

We can use Equation (1) and Equation (2) to derive the retailer's advertising investment level and the return rate of waste products.

$$
\begin{gathered}
\frac{\partial \pi_{m}}{\partial \tau}=\Delta(\alpha-\beta p+\lambda g)+\theta-2 h \tau \\
\frac{\partial \pi_{r}}{\partial g}=\lambda(p-w)-g
\end{gathered}
$$

Solving the two functions above simultaneously, the optimal solutions can be derived.

Theorem 1: The optimal decision results of the manufacturer and the retailer are as follows:

$$
\begin{gathered}
g_{r}^{C}=\lambda(p-w) \\
\tau_{m}^{C}=\frac{\Delta\left[\alpha-\beta p+\lambda^{2}(p-w)\right]+\theta}{2 h}
\end{gathered}
$$

\subsection{Model M-Only the manufacturer undertakes the CSR}

In this model, only the manufacturer undertakes the CSR, the retailer does not share the CSR. The profit function and social welfare function of CLSC members are as follow:

$$
\begin{gathered}
\operatorname{Max} \pi_{r}^{M}=(p-w)(\alpha-\beta p+\lambda g)-\frac{1}{2} g^{2} \\
\operatorname{Max} V_{m}^{M}=\pi_{m}+r C S \\
=\left(w-c_{n}+\Delta \tau\right)(\alpha-\beta p+\lambda g)+\theta\left(\tau-\tau_{0}\right) \\
-h \tau^{2}+r \frac{(\alpha-\beta p+\lambda g)^{2}}{2 \beta}
\end{gathered}
$$

We can use Equation (8) and Equation (9) to derive the retailer's advertising investment level and the return rate of waste products.

$$
\begin{gathered}
\frac{\partial V_{m}}{\partial \tau}=\Delta(\alpha-\beta p+\lambda g)+\theta-2 h \tau \\
\frac{\partial \pi_{r}}{\partial g}=\lambda(p-w)-g
\end{gathered}
$$

Solving the two functions above simultaneously, the optimal solutions can be derived.

Theorem 2: The optimal decision results of the manufacturer and the retailer are as follows:

$$
g_{r}^{M}=\lambda(p-w)
$$

$$
\begin{gathered}
\tau_{m}^{M}=\frac{\Delta\left[\alpha-\beta p+\lambda^{2}(p-w)\right]+\theta}{2 h} \\
V_{s}^{M}=V_{m}^{M}+\pi_{r}^{M}=\left(p-c_{n}+\Delta \tau\right)\left[\alpha-\beta p+\lambda^{2}(p-w)\right] \\
+\theta\left\{\frac{\Delta\left[\alpha-\beta p+\lambda^{2}(p-w)\right]+\theta}{2 h}-\tau_{0}\right\}-h\left\{\frac{\Delta\left[\alpha-\beta p+\lambda^{2}(p-w)\right]+\theta}{2 h}\right\}^{2}+ \\
r \frac{\left(\alpha-\beta p+\lambda^{2}(p-w)\right)^{2}}{2 \beta}-\frac{1}{2}[\lambda(p-w)]^{2}
\end{gathered}
$$

\subsection{Model R-Only the retailer undertakes the CSR}

In this model, only the retailer undertakes the CSR, the manufacturer does not share the CSR. The profit function and social welfare function of CLSC members are as follow:

$$
\begin{gathered}
\operatorname{Max} \pi_{m}^{R}=\left(w-c_{n}+\Delta \tau\right)(\alpha-\beta p+\lambda g)_{h \tau^{2}}^{+}+\theta\left(\tau-\tau_{0}\right)- \\
\operatorname{Max} V_{r}^{R}=\pi_{r}+r C S \\
=(p-w)(\alpha-\beta p+\lambda g)-\frac{1}{2} g^{2}+r \frac{(\alpha-\beta p+\lambda g)^{2}}{2 \beta}
\end{gathered}
$$

We can use Equation (15) and Equation (16) to derive the retailer's advertising investment level and the return rate of waste products.

$$
\begin{gathered}
\frac{\partial \pi_{m}}{\partial \tau}=\Delta(\alpha-\beta p+\lambda g)+\theta-2 h \tau \\
\frac{\partial V_{r}}{\partial g}=\lambda(p-w)-g+\frac{(\alpha-\beta p) \lambda r+r \lambda^{2} g}{\beta}
\end{gathered}
$$

Solving the two functions above simultaneously, the optimal solutions can be derived.

Theorem 3: The optimal decision results of the manufacturer and the retailer are as follows:

$$
\begin{gathered}
g_{r}^{R}=\frac{\lambda \beta(p-w)+\lambda r(\alpha-\beta p)}{\beta-r \lambda^{2}} \\
\tau_{m}^{R}=\frac{\Delta\left[\alpha-\beta p+\frac{\lambda^{2} \beta(p-w)+\lambda^{2} r(\alpha-\beta p)}{\beta-r \lambda^{2}}\right]+\theta}{2 h} \\
V_{s}^{R}=V_{r}^{R}+\pi_{m}^{R} \\
\theta\left\{\frac{\Delta\left[\alpha-\beta p+\frac{\lambda^{2} \beta(p-w)+\lambda^{2} r(\alpha-\beta p)}{\beta-r \lambda^{2}}\right]+\theta}{2 h}-\tau_{0}\right\}- \\
h\left\{\frac{\Delta\left[\alpha-\beta p+\frac{\lambda^{2} \beta(p-w)+\lambda^{2} r(\alpha-\beta p)}{\beta-r \lambda^{2}}\right]+\theta}{2 h}\right\}^{2}+r \frac{\left[\alpha-\beta p+\frac{\lambda^{2} \beta(p-w)+\lambda^{2} r(\alpha-\beta p)}{\beta-r \lambda^{2}}\right]^{2}}{2 \beta}- \\
\frac{1}{2}\left[\frac{\lambda \beta(p-w)+\lambda r(\alpha-\beta p)}{\beta-r \lambda^{2}}\right]^{2}
\end{gathered}
$$

\subsection{Model MR-The manufacturer and the retailer share CSR}

In this model, both the manufacturer and the retailer undertake the CSR. The social welfare functions of CLSC members are as follow:

$$
\begin{array}{r}
\operatorname{Max} V_{m}^{M R}=\pi_{m}+k r=\left(w-c_{n}+\Delta \tau\right)(\alpha-\beta p+\lambda g)+ \\
\theta\left(\tau-\tau_{0}\right)-h \tau^{2}+k r \frac{(\alpha-\beta p+\lambda g)^{2}}{2 \beta}
\end{array}
$$

$$
\begin{gathered}
\operatorname{Max} V_{r}^{M R}=\pi_{r}+(1-k) r C S=(p-w)(\alpha-\beta p+\lambda g)- \\
\frac{1}{2} g^{2}+(1-k) r \frac{(\alpha-\beta p+\lambda g)^{2}}{2 \beta}
\end{gathered}
$$


We can use Equation (22) and Equation (23) to derive the retailer's advertising investment level and the return rate of waste products

$$
\begin{array}{r}
\frac{\partial V_{m}}{\partial \tau}=\Delta(\alpha-\beta p+\lambda g)+\theta-2 h \tau \\
\frac{\partial V_{r}}{\partial g}=\lambda(p-w)-g+\frac{(1-k)\left[(\alpha-\beta p) \lambda r+r \lambda^{2} g\right]}{\beta}
\end{array}
$$

Solving the two functions above simultaneously, the optimal solutions can be derived.

Theorem 4: The optimal decision results of the manufacturer and the retailer are as follows:

$$
\begin{gathered}
g_{r}^{M R}=\frac{\lambda \beta(p-w)+\lambda r(1-k)(\alpha-\beta p)}{\beta-r \lambda^{2}(1-k)} \\
\tau_{m}^{M R}=\frac{\Delta\left[\alpha-\beta p+\frac{\lambda^{2} \beta(p-w)+\lambda^{2} r(1-k)(\alpha-\beta p)}{\beta-r \lambda^{2}(1-k)}\right]+\theta}{2 h} \\
=\left(p-c_{n}+\Delta \tau\right)\left[\alpha-\beta p+\frac{\lambda^{2} \beta(p-w)+\lambda^{2} r(1-k)(\alpha-\beta p)}{\beta-r \lambda^{2}(1-k)}\right]+ \\
\theta\left\{\frac{\Delta\left[\alpha-\beta p+\frac{\lambda^{2} \beta(p-w)+\lambda^{2} r(1-k)(\alpha-\beta p)}{\beta-r \lambda^{2}(1-k)}\right]+\theta}{2 h}-\tau_{0}^{M R}\right\}- \\
h\left\{\frac{\Delta\left[\alpha-\beta p+\frac{\lambda^{2} \beta(p-w)+\lambda^{2} r(1-k)(\alpha-\beta p)}{\beta-r \lambda^{2}(1-k)}\right]+\theta}{2 h}\right\}^{2}+ \\
r \frac{\left[\alpha-\beta p+\frac{\lambda^{2} \beta(p-w)+\lambda^{2} r(1-k)(\alpha-\beta p)}{\beta}\right]^{2}}{2 \beta}-\frac{1}{2}\left[\frac{\lambda \beta(p-w)+\lambda r(1-k)(\alpha-\beta p)}{\beta-r \lambda^{2}(1-k)}\right]^{2}
\end{gathered}
$$

Proposition 1: In the three CSR sharing models of CLSC and the basic model, the optimal advertising investment levels are

Proof of proposition 1:

$$
g^{R}>g^{M R}>g^{M}=g^{C}
$$

It is easy to prove that

$$
g^{M}=g^{C}=\lambda(p-w)
$$

$g^{M R}-g^{M}=\frac{r \lambda^{3}(p-w)(1-k)+\lambda r(1-k)(\alpha-\beta p)}{\beta-r \lambda^{2}(1-k)}>0$

Due to $0<1-k<1$,

$\frac{1}{\beta-r \lambda^{2}}>\frac{1}{\beta-r \lambda^{2}(1-k)}, \lambda \beta(p-w)+\lambda r(\alpha-\beta p)>$

$\lambda \beta(p-w)+\lambda r(1-k)(\alpha-\beta p)$

We have $\quad g^{R}=\frac{\lambda \beta(p-w)+\lambda r(\alpha-\beta p)}{\beta-r \lambda^{2}}>$

$\frac{\lambda \beta(p-w)+\lambda r(1-k)(\alpha-\beta p)}{\beta-r \lambda^{2}(1-k)}=g^{M R}$

Hence, we have the comparison sequence of advertising investment levels: $g^{R}>g^{M R}>g^{M}=g^{C}$

Proposition 2: In the three CSR sharing models of CLSC and the basic model, the optimal waste product return rates are

$$
\tau^{R}>\tau^{M R}>\tau^{M}=\tau^{C}
$$

Proof of proposition 2: Similar to the proof of proposition 1 , it is easy to have the comparison sequence of waste product's return rates: $\tau^{R}>\tau^{M R}>\tau^{M}=\tau^{C}$

\section{Simulation analysis}

Assumes the initial value of parameters are as follows:

Table2. Initial value of parameters

\begin{tabular}{|c|c|c|c|c|c|c|}
\hline$w$ & $p$ & $c_{n}$ & $c_{r}$ & $\Delta$ & $r$ & $\alpha$ \\
\hline 60 & 80 & 50 & 45 & 5 & 0.3 & 200 \\
\hline
\end{tabular}

\begin{tabular}{|c|c|c|c|c|c|c|}
\hline$\beta$ & $\lambda$ & $k$ & $\tau_{0}$ & $h$ & $\theta$ & \\
\hline 1 & 0.6 & 0.6 & 0.5 & 400 & 10 & \\
\hline
\end{tabular}

The specific simulation analysis results are as follows:

Table3. Simulation analysis results

\begin{tabular}{c|c|c|c|c}
\hline & Model C & Model M & Model R & Model MR \\
\hline$\tau$ & 0.8075 & 0.8075 & 0.9038 & 0.8434 \\
$g$ & 12 & 12 & 37.6682 & 21.5719 \\
$\pi_{m}$ & 1527.823 & 1527.823 & 1747.719 & 1608.957 \\
$\pi_{r}$ & 2472 & 2472 & 2142.573 & 2426.189 \\
$V_{m}$ & -- & 3954.799 & -- & 3199.607 \\
$V_{r}$ & -- & -- & 5192.825 & 3486.622 \\
$V_{s}$ & -- & 6426.799 & 6940.544 & 6686.229 \\
\hline
\end{tabular}

These results further prove the correctness of Proposition 1 and Proposition 2.

According to the initial values, the following trend charts are used to analyze the influence of the extent to which CLSC members undertake CSR on various decision variables:

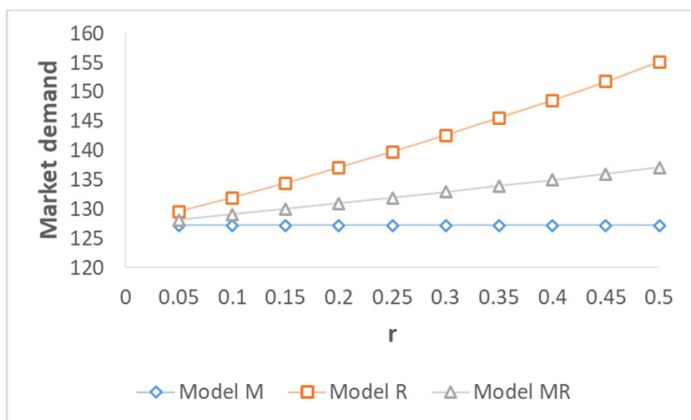

Figure 2 Market demand differences as a function of $r$

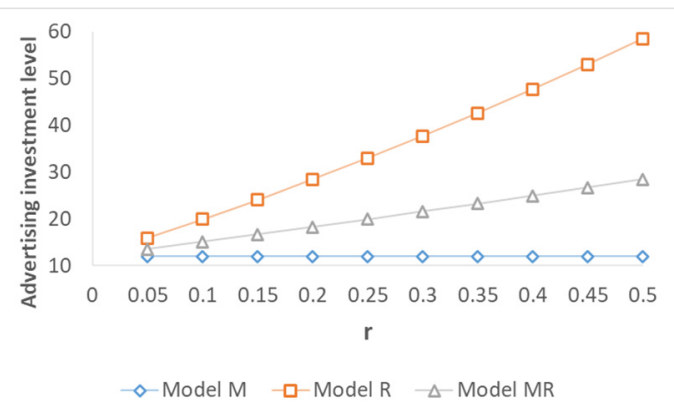

Figure 3 Adverting investment level differences as a function of $r$

Figure 3 and proposition 1 illustrates that advertising investment level represents differently in different models. Under model $\mathrm{R}$ and model $\mathrm{MR}$, the advertising investment level is increasing with the increase of the extent to members undertake CSR, indicating that when only the retailer undertakes CSR and when the manufacturer and the retailer jointly undertake the CSR, the retailer are required to expend the investment in advertising. Under model $\mathrm{M}$, as the extent to manufacturer undertakes CSR increases, the advertising investment level remains unchanged, indicating that there is no impact on the advertising investment decision of retailer when only the manufacturer undertakes CSR. 


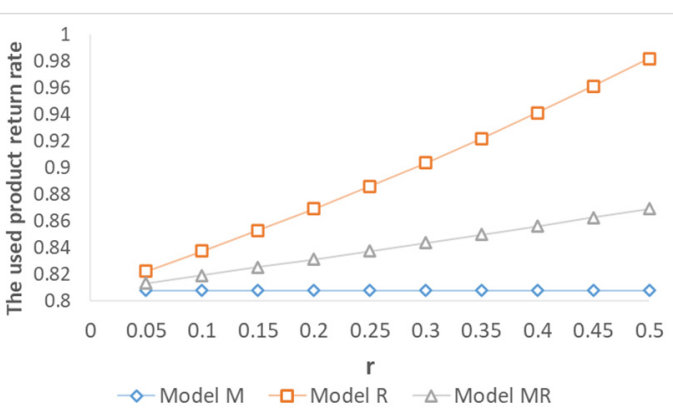

Figure 4 Waste products' return rate differences as a function of $r$

Like the advertising investment level, we observe that the waste products return rate is also varying in different models from Figure 4 and proposition 2. Under model R and model MR, the waste products' return rate is increasing with the increase of the extent to members undertake CSR, indicating that it is conducive to promoting the recycling of waste products in the CLSC when only the retailer undertakes CSR and when the manufacturer and the retailer share the CSR. Under model $\mathrm{M}$, as the extent to manufacturer undertakes CSR increases, the return rate remains unchanged, which means that only the manufacturer undertakes CSR has no impact on the recycling of waste products in the CLSC.

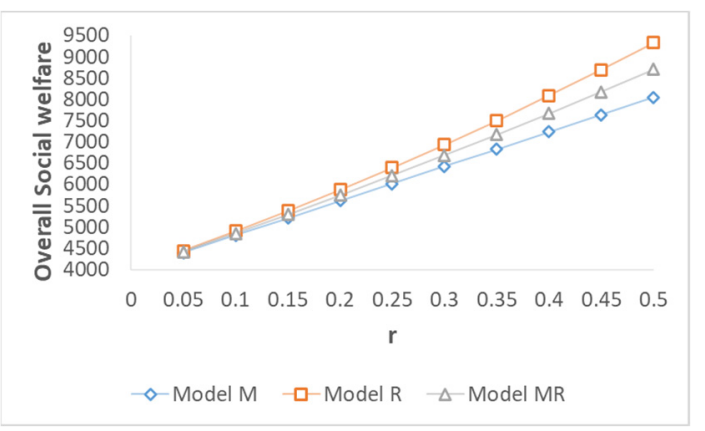

Figure 5 Social welfare differences as a function of $r$

Figure 5 shows that the overall social welfare is increasing with the increase of the extent to members undertake CSR no matter which member undertake CSR. Moreover, the overall social welfare reaches the highest under model $\mathrm{R}$, revealing that it is most conducive to improving the overall efficiency of the CLSC when only the retailer undertakes the CSR.

From the figures presented above, we can know that as the level of the chain member undertaking CSR is higher, taking the interest of consumers in account, the wholesale price and retail price will be lower, and thus lead to more market demand. Therefore, in order to meet the expanding demand, more advertisement should be invested. And due to more market demand, the manufacturer will also increase the waste products return rate. Ultimately, the utility of manufacturer and retailer will increase. Therefore, the overall social welfare of the supply chain will increase.

\section{Conclusion}

Considering a CLSC consisting of a manufacturer and a retailer, we constructed three different models to explore the effects of CSR behavior on the advertising investment level and waste products return rate. What is more, we take the government's RPM into account. Bases on model analysis and simulation results, we can draw the following conclusions:

(1) It contributes to accelerate the recycling of used products when only the retailer undertakes CSR and when the manufacturer and the retailer jointly undertake CSR.

(2) When only the retailer undertakes CSR and when the manufacturer and the retailer share CSR, the retailer should invest more in advertising.

(3) No matter which member undertakes CSR or share CSR, the overall social welfare will increase, and will reach the highest when only the retailer undertakes CSR.

\section{Acknowledgment}

This research is supported by National Natural Science Foundation of China under Grant 72001147 and Guangdong Planning Project of Philosophy and Social Science of China under Grant GD19YGL18.

\section{References}

1. R. Canan Savaskan, Shantanu Bhattacharya, Luk N. Van Wassenhove. Closed-Loop Supply Chain Models with Product Remanufacturing. 2004, 50(2)

2. Atalay Atasu, L. Beril Toktay, Luk N. Van Wassenhove. How Collection Cost Structure Drives a Manufacturer's Reverse Channel Choice. 2013, 22(5):1089-1102.

3. Ata Allah Taleizadeh, Nima Alizadeh-Basban, Seyed Taghi Akhavan Niaki. A closed-loop supply chain considering carbon reduction, quality improvement effort, and return policy under two remanufacturing scenarios. 2019, 232:1230-1250.

4. Wenbin Wang, Yu Zhang, Kai Zhang, et al. Rewardpenalty mechanism for closed-loop supply chains under responsibility-sharing and different power structures. 2015, 170:178-190.

5. Wenbin Wang, Lingling Fan, Peng Ma, et al. Rewardpenalty mechanism in a closed-loop supply chain with sequential manufacturers' price competition. 2017

6. Kim Sungki, Shin Nina, Park Sangwook. ClosedLoop Supply Chain Coordination under a RewardPenalty and a Manufacturer's Subsidy Policy. 2020, 12(22):9329-9329.

7. Shibaji Panda, Nikunja Mohan Modak, Leopoldo Eduardo Cárdenas-Barrón. Coordinating a socially responsible closed-loop supply chain with product recycling. 2017, 188:11-21.

8. Nikunja Mohan Modak, Nima Kazemi, Leopoldo Eduardo Cárdenas-Barrón. Investigating structure of a two-echelon closed-loop supply chain using social work donation as a Corporate Social Responsibility 
practice. 2018

9. Seyyed-Mahdi Hosseini-Motlagh, Samira Ebrahimi, Roza Zirakpourdehkordi. Coordination of dualfunction acquisition price and corporate social responsibility in a sustainable closed-loop supply chain. 2020, 251

10. Wang Yuyan, Su Mei, Shen Liang, et al. Decisionmaking of closed-loop supply chain under Corporate Social Responsibility and fairness concerns. 2021, 284

11. Xianpei Hong, Lei $\mathrm{Xu}$, Peng $\mathrm{Du}$, et al. Joint advertising, pricing and collection decisions in a closed-loop supply chain. 2015, 167:12-22.

12. Régis Y. Chenavaz, Gustav Feichtinger, Richard F. Hartl, et al. Modeling the impact of product quality on dynamic pricing and advertising policies. 2020, 284(3):990-1001.

13. Ata Allah Taleizadeh, Maryam Karimi Mamaghan, Seyed Ali Torabi. A possibilistic closed-loop supply chain: pricing, advertising and remanufacturing optimization. 2020, 32(4):1195-1215.

14. Guo Junhua, Li Bangyi, Ni Ming. The Selection of Take-Back Model of Remanufacturing Closed-Loop Supply Chain Based on WTP Differentiation[J]. Chinese Journal of Management, 2015,12(01):142147.

15. Xu Minli, Guo Shuang, Jian Huiyun. Research on Closed-Loop Supply Chain Decision Considering Corporate Social Responsibility and Advertising Effect [J]. Chinese Journal of Management, 2019,16(04):615-623. 